\title{
Letters
}

Website: bmj.com

Email: letters@bmj.com

\section{The NHS plan}

\section{Plan represents considerable privatisation}

EDITOR-Dixon and Dewar's editorial welcomes the considerable injection of money promised in the NHS plan and claims that the plan is true to the NHS's founding principles. ${ }^{1}$ Yet Aneurin Bevan's greatest achievement, and not one demanded of him by the Beveridge report, was the nationalisation of hospitals. He recognised that ownership was important, because with ownership comes control.

The NHS plan promises 100 new hospitals by 2010 ( 69 of which are already in the pipeline). This will involve £7bn of new investment under the private finance initiative. Together with the new plans for some NHS operating to be carried out in the private sector, the NHS plan represents a larger privatisation than even the Tories planned.

Curiously, the plan also recognises the failure of past privatisations. I remember unsuccessfully voting against the privatisation of cleaning at the London Hospital when I was a board member of the old Tower Hamlets Health Authority. Squalid wards followed, and they remain with us now. The plan recognises that this policy was a disaster.

\section{Advice to authors \\ We prefer to receive all responses electronically, sent either directly to our website or to the editorial office as email or on a disk. Processing your letter will be delayed unless it arrives in an electronic form. \\ We are now posting all direct submissions to our website within 24 hours of receipt and our intention is to post all other electronic submissions there as well. All responses will be eligible for publication in the paper journal. \\ Responses should be under 400 words and relate to articles published in the preceding month. They should include $\leqslant 5$ references, in the Vancouver style, including one to the BMJ article to which they relate. We welcome illustrations. \\ Please supply each author's current appointment and full address, and a phone or fax number or email address for the corresponding author. We ask authors to declare any competing interest. Please send a stamped addressed envelope if you would like to know whether your letter has been accepted or rejected. \\ Letters will be edited and may be shortened. \\ bmj.com \\ letters@bmj.com}

BMJ VOLUME 321 21 OCTOBER 2000 bmj.com
Altogether $£ 30 \mathrm{~m}$ of cash is to be injected into hospital trusts before the next election to pay for the consequences of this mistaken minor privatisation. How much money will we have to spend in five, 10 , or 20 years' time to correct the disastrous policy of major privatisation that we are now heading for? $\mathrm{Mr}$ Milburn, think again, before it is too late.

Kambiz Boomla general practitioner

Chrisp Street Health Centre, London E14 6PG

k.boomla@qmw.ac.uk

1 Dixon J, Dewar S. The NHS plan. BMJ 2000;321:315-6. (5 August.)

Plan puts patients first, but who will want to care for them?

EDITOR - I am the wife of a surgeon. We have been married throughout his training and have two preschool children. I am not in the medical profession. I have watched the system erode the drive and enthusiasm of someone who set out on his medical career with a total commitment to the NHS.

Over the past eight years, as a requirement of my husband's training, we have moved house numerous times. We received little help with finding new homes, and the removal expenses we received rarely covered our costs. We have paid for many surgical and managerial courses, conferences, textbooks, and journals. There are no tax breaks for any of these as none is deemed necessary for performing the function of surgeon.

The hours that my husband has worked over the years have been in contravention of the health and safety legislation as it applies to most other professionals. This time and effort have been expected and consequently often unacknowledged. At less than half pay his contracted overtime was certainly unrewarded.

He has had no control but a lot of responsibility. Long unsociable hours, weekends on call, nights without sleep, catching up with hospital paperwork, preparing talks, reading the latest journals, studying for exams, and writing papers in his "spare" time; these leave little time for family life. This lifestyle has made continuing with my career impossible.

Why have we done this? I envisaged that my husband would continue to devote his energy and talent to the NHS but that we would be able to provide a home and stable environment for our family-not a palatial mansion, the cost of which is many hours worked in the private system and often relationship, but a reasonable home. When I read about the proposal to ban new consultants from doing any private work for seven years I felt exasperated. ${ }^{1}$ On a current consultant wage with no private income I doubt we will be able to buy a three bedroom house in the south east within a specified radius of a hospital.

I am sorry Mr Blair, but I do not think that my aspirations for some family life and a home are ridiculous. If acceptance of a new consultant contract cannot fulfil them I will encourage my husband to leave the health service and, if necessary, the United Kingdom.

Susan Tyler wife of surgeon

4 Eaton Gate, Northwood, Middlesex HA6 2NN

1 Dixon J, Dewar S. The NHS plan. BMJ 2000;321:315-6. (5 August.)

BMA representatives must negotiate for the NHS as it will be

EDITOR-It is depressingly predictable that BMA representatives (Dr Ian Bogle and Dr Peter Hawker) should focus on the private practice issue in commenting on the NHS plan. ${ }^{1}$ What I want from them, if they are going to represent me, is that they consider, firstly, what the NHS will need from its consultants and, secondly, what consultants will need from the NHS

Surely it is becoming increasingly obvious that the medical component of a modern health service needs to be delivered by trained doctors (supported in tasks that don't need a doctor by nurses and other professions). Yes, it's true that registrars can do a good job, but they don't all and they don't always. We should not continue to rely on doctors in training for the bulk of routine treatment decisions, and we should progress in the direction set by the Calman changes towards shorter and more focused training, so that registrars are no longer the workhorses of the NHS.

A modern health service will need to ensure that its trained staff are present within the workplace and undertaking NHS work during the hours that they are contracted to work. Any government would want to achieve this, so the only two alternatives are to get consultants to do it or create a trained subconsultant grade. If we think it should be consultants (and I do) then we can't be doing private work at the same time as providing our NHS service. It will of course lead to other changes, such as consultants in some specialties being on a rota to work at night and weekends and others having more unsocial calls. 
What do consultants need in return? Greater numbers (including the disappearance of singlehanded consultants); time off in the day for hours worked at night; and to lose 24 hour, seven day a week responsibility for patients, so that an off duty consultant has no contractual obligation to the NHS. The private practice problem then disappears-if you are not contractually bound to employer $\mathrm{A}$ at a particular time then you can choose to be working elsewhere.

I want my BMA representatives to get on with negotiating for the NHS as it will be, not as it has been

Eric Crouch consultant psychiatrist Barnsley District General Hospital, Barnsley S75 2EP

ecrouch@macline.co.uk

Competing interests: I spent five years as a clinical director and dare to take the management view.

1 MacDonald R. Plan leaves England "with third division" health service. $B M J$ 2000;321:318. (5 August.)

\section{Private finance scheme for Worcester}

\section{Journal has not presented balanced picture of modern health planning}

EDITOR-Ferriman's news item on Worcestershire's service reconfiguration ${ }^{1}$ failed to reflect a balanced view of the inaccuracies in the report Deficits before Patients. ${ }^{2}$ This lack of balance reflects a consistent bias against the private finance initiative in the $B M J$.

The details are probably not of interest to most of the journal's readers. But it is important to note that several claims made in the report about the rising cost of the private finance initiative hospital in Worcester and the reduction in bed numbers are inaccurate.

Two points in the debate do merit wider discussion. Why do we still measure the health service by the number of acute beds when service provision has moved so far beyond that narrow view? Our local strategy is based on a holistic view of health care that integrates primary, intermediate, and secondary care. We use community hospital and nursing home beds as a key part of our overall service for ill patients, yet we are stuck with a definition that says "community beds don't count."

In examining bed numbers why do we not consider the number of people who might need them? Worcestershire scores low on virtually all indicators of morbidity and all predictors of morbidity such as deprivation scores. ${ }^{3}$ Why then should we not aim to have fewer acute beds than other, more ill, populations?

I am concerned that the $B M J$ has adopted a stance that is consistently against the private finance initiative and has not presented a balanced picture of modern health planning. It is perfectly reasonable for the journal to develop and promulgate its editorial policy on the initiative, but it should still be prepared to present the arguments from both sides. Recent news items and editorials have focused only on the anti-private finance initiative message, and an Education and Debate series gave an unusually large amount of space to those who opposed the initiative. Even an article that included an attack on Colin Reeves, of the NHS Executive, cited only references to articles in the journal that were against the initiative $^{4}$ and none to letters that put forward a different argument. ${ }^{5}$

The future configuration of hospitals, within the overall planning of comprehensive health services, is an important issue. Debate should not be confined simply to how the government wants to fund acute hospital buildings.

B McCloskey director of public health

Worcestershire Health Authority, Worcester WR4 9RW

Brian.McCloskey@wha.worcester-ha.wmids.nhs.uk

1 Ferriman A. Private finance scheme for Worcester "will cu beds." BMJ 2000;230:1625. (17 June.)

2 Pollock A, Price D, Dunnigan M. Deficits before patients: report on the Worcester Royal Infirmary PFI and Worcestershir hospital reconfiguration. London: School of Public Policy, University College London, 2000.

3 McCloskey B. Annual reports of the director of public health Worcester: Worcestershire Health Authority, 1989-2000.

Jones J. The private finance initiative: spinning out the defence. $B M J$ 2000;320:1460-1. (27 May.)

5 McCloskey B, Deakin M. Private finance initiative. $B M$ 2000;320:251. (22 January.)

Battle in Kidderminster is against "spin," half truth, and obfuscation

EDITOR-Ferriman ${ }^{1}$ has written about Pollock et al's report on the changes to health services in Worcestershire. ${ }^{2}$ The response of Worcestershire Health Authority and other government agencies is not to answer the legitimate questions posed by the report but to deny its accuracy and to attempt to denigrate the authors' work; Pollock is a known critic of the private finance initiative scheme espoused by both major political parties.

Our battle in Kidderminster is against "spin," half truth, and obfuscation. The health secretary, the public health minister, the NHS Executive (West Midlands), Worcestershire Health Authority, and the MP for Wyre Forest (David Lock) all make similar comments. They say, for example, "The hospital in Kidderminster is not closing." But it is losing its accident and emergency department and all acute inpatient beds. If that is not closure of an acute general hospital what is?

They also say: " $90 \%$ of patients currently treated at Kidderminster Hospital will still be treated there." Of course they will because this is the approximate proportion that attend as outpatients and day cases at any acute general hospital. But $100 \%$ of acute inpatients will have to travel further for their treatment.

"The new hospital will have 474 acute beds; this is an increase of 84 acute beds over the original 390. I can confirm that these are all acute beds" (P Archer-Jones, chief executive, Worcestershire Health Authority, personal communication 17 June 2000). The full business case for the new hospital states that of these 474 beds, actually only 336 are acute beds.
Ms Yvette Cooper, parliamentary under secretary of state for health, maintained the confusion by answering opposition MPs in an adjournment debate on 25 July by citing figures from Worcestershire Health Authority: "After the new hospital opens, there will be 988 such [acute] beds." Where are these 988 acute beds? It is impossible for the missing 652 to be in the other acute general hospital in the county at Redditch.

The chief executive of the new Worcestershire Acute Hospitals Trust dismisses questions about bed numbers by saying that they are "not an accurate or sensible indicator of health care provision" (R Harrison, personal communication 23 June 2000).

Is the true state of affairs being concealed from ministers? Or are Pollock et al correct, as the Kidderminster Hospital Campaign and Health Concern believes, and the new hospital in Worcester is unaffordable without the ravaging of Kidderminster that then becomes a political necessity?

Richard T Taylor consultant physician (retired) Kidderminster Hospital Campaign and Health Concern, PO Box 1823, Kidderminster DY10 6WZ RTT@rtact.freeserve.co.uk

Competing interests: Dr Taylor is chairman of Kidderminster Hospital Campaign and Health Concern.

1 Ferriman A. Private finance scheme for Worcester "will cut beds." BMJ 2000;320:1625. (17 June.)

2 Pollock A, Price D, Dunnigan M. Deficits before patients: a report on the Worcester Royal Infirmary PFI and Worcestershire hospital reconfiguration. London: School of Public Policy, University College London, 2000.

3 Worcester Royal Infirmary NHS Trust Proposals for a new hospital in Worcester. Full business case as approved by NHS hospital in Worcester. Full business case as approved by NHS Worcester Royal Infirmary NHS Trust, 1999.

\section{Meta-analysis of increased inhaled steroid or addition of salmeterol in asthma}

\section{Researchers can learn from industry based reporting standards}

EDITOR-The meta-analysis of inhaled salmeterol compared with inhaled steroids by Shrewsbury et $\mathrm{al}^{1}$ is a fine counter example to recent controversial claims that the standard of industry sponsored meta-analyses in asthma is inferior to that of other metaanalyses. ${ }^{2}$ Nevertheless, the paper raises one general difficulty with the reporting of metaanalyses.

In referring to the quality of individual studies the authors write: "In all studies, appropriate methods were used for summarising and comparing treatments, and methods for handling missing data were preplanned" ( $p$ 1368). If, as was almost certainly the case, the studies were carried out to the pharmaceutical industry's standards, the analyses will also have been preplanned as required by the guidelines of the International Conference on Harmonisation. ${ }^{3}$ It does not follow, however, that this is necessarily the analysis that found its way into print, or even the one that was used for this meta-analysis.

The version published by investigators is often inferior, as regards statistical analysis, 
to that presented to the regulator. This is because editors are less exacting and readers are less tolerant when it comes to statistics than are regulators; sponsors cannot control publications to the same extent as they do trial reports.

It seems unlikely that the scale on which Shrewsbury et al chose to summarise outcomes will have been the same as that in the original trials, which may have varied from trial to trial. This raises the question of prespecification of methods for metaanalysis. For example, the authors chose the binary probability scale for the outcome "exacerbation." But the original scale was "ordered categorical," which suggests logistic regression. Furthermore, a summary on the log-odds scale (the usual default) for the data presented in their paper would disagree with their finding that salmeterol is significantly better than steroid. For example, a fixed effects analysis gives an odds ratio of 0.87 with a $95 \%$ confidence interval of 0.74 to 1.03 , straddling 1 .

I hope that pharmaceutical companies will not only follow Sykes's call to publish all clinical trials ${ }^{4}$ but also have detailed summaries (as provided to regulators) available on the web as well. Not only would this increase confidence in industry based meta-analyses but it would allow researchers to learn from industry based reporting standards.

Stephen Senn professor of pharmaceutical and health statistics

University College London, London WC1E 6BT stephens@public-health.ucl.ac.uk

Competing interests: Professor Senn is a consultant to the pharmaceutical industry.

1 Shrewsbury S, Pyke S, Britton M. Meta-analysis of increased dose of inhaled steroid or addition of salmeterol in symptomatic asthma (MIASMA). BMJ 2000;320:136873. (20 May)

2 Jadad AR, Moher M, Browman GP, Booker L, Sigouin C, Fontes M, et al. Systematic reviews and meta-analyses on treatment of asthma: critical evaluation. BMJ 2000; 320:537-40. (26 February)

3 International Conference on Harmonisation. Statistical principles for clinical trials. Stat Med 1999;18:1905-42

4 Sykes R. Being a modern pharmaceutical company. BMJ 1998;317:1172-80

\section{Greening et al's study should not have been included}

EDITOR-The introduction to Shrewsbury et al's meta-analysis begins: "The 1997 British Guidelines on Asthma Management acknowledged the landmark study of Greening et al."1 The paragraph in the methods section headed "Quality assessment" begins: "All included studies were sponsored by GlaxoWellcome and all met company-wide minimum quality thresholds." The paragraph finishes with a sentence beginning: "In all studies, appropriate statistical methods were used for summarising and comparing treatments." I am surprised that the authors included Greening et al's study in the meta-analysis. ${ }^{2}$ It is apparent from its methodology that a confounder was introduced that rendered the results uninterpretable.

The study states, "During the 6-month treatment period patients received either beclomethasone diproprionate (BDP) (200 $\mu \mathrm{g}$ twice daily by metered dose aerosol inhaler (MDI)) plus salmeterol (50 $\mu \mathrm{g}$ twice daily by Diskhaler) or higher dose BDP (500 $\mu \mathrm{g}$ twice daily by MDI) plus placebo."' These two arms of the treatment phase were randomised after an initial two week run in period, during which patients took inhaled beclomethasone diproprionate $(200 \mu \mathrm{g}$ twice daily), while bronchodilators were replaced with salbutamol (by Diskhaler) to be used as required.

Both arms of the study used beclomethasone diproprionate via a metered dose inhaler, but salmeterol via a Diskhaler was selected for addition to the lower dose arm. Thus the treatment phase compared an increased dose of beclomethasone diproprionate via metered dose inhaler with added salmeterol via a Diskhaler.

It would be difficult to conclude whether any significant difference between the two groups was due to the salmeterol or the use of a breath actuated Diskhaler. In other words, any benefits to the patients may be assumed to have been due to the added salmeterol but may have been due to the better inhaler device.

The dry powdered breath actuated Diskhaler has inherent advantages over the aerosol metered dose inhaler, and it is therefore difficult to interpret this study's conclusions. I have discussed the methodological flaw with many of GlaxoWellcome's representatives, all of whom acknowledge the methodological design fault. It is therefore surprising to see this study included in Shrewsbury et al's meta-analysis. An independently conducted meta-analysis reviewing all long acting $\beta_{2}$ agonists would be more credible.

Finally, as stated in the competing interests statement, two of the three authors work for GlaxoWellcome and the third has shares in the company. I am concerned about the potential conflict of interests when pharmaceutical companies perform meta-analyses of their own sponsored trials in reputable journals.

\section{A D Greig general practitioner}

Bourne Valley Practice, Ludgershall, Andover, Hampshire SP11 9TA

roskoff@msn.com

Competing interests: Dr Greig has been paid as a speaker by both Allen and Hanbury and Astra Pharmaceuticals. 1 Shrewsbury S, Pyke S, Britton M. Meta-analysis of increased dose of inhaled steroid or addition of salmeterol in symptoma

73. (20 May.)
Greening AP, Ind PW, Northfield M, Shaw G. Added salm2 Greening AP, Ind PW, Northfield M, Shaw G. Added salm-
eterol verses higher-dose corticosteroid in asthm eterol verses higher-dose cor
patients. Lancet 1994;344:523-9.

\section{Study should have been more thorough}

EDITOR-Shrewsbury et al's meta-analysis of studies sponsored by GlaxoWellcome was not systematic and has many pitfalls that need to be addressed. ${ }^{1}$ The authors restricted themselves to only three databases in their search for studies. Electronic searches of the literature may identify as few as half of the relevant studies. ${ }^{2}$ Use of the Cochrane Airways Group (St George's Hospital Medical School, London) database of randomised controlled trials could have resulted in the inclusion of further studies.
This database not only includes studies from other electronic databases but also incorporates systematic hand searching (retrospective and prospective) of many core journals in respiratory disease in an attempt to improve the thoroughness of electronic searching in this subject.

The authors failed to apply independently validated methodological quality assessment criteria to the included studies and instead used in-house assessments, for which little detail is provided. Readers are unable to judge the quality of included studies. The authors noted heterogeneity in symptom scores and rescue treatment but failed to conduct any sensitivity analysis (for example, dose or type of inhaled steroid, severity of asthma, or study quality). A metaanalysis should be planned and conducted with predefined subgroup analyses based on clinical predictions.

The authors noted that the heterogeneity is "almost certainly clinically unimportant" since the difference between the fixed and random effects models is small. Changing from a fixed to a random effects model tells you little if anything about the clinical importance of heterogeneity. If it does not make statistical sense (significant heterogeneity) to combine results it certainly won't be worth deriving any clinical conclusions from the outcome in question. Use of additional rescue bronchodilator is an important indicator of the efficacy of salmeterol, and symptoms are an important patient oriented outcome measure. A formal sensitivity analysis based on at least some of the above criteria should be explored.

As with any trial, when a meta-analysis is published it should provide readers with enough information for them to be able to duplicate the study. In this case most readers would have difficulty since unreported inhouse quality assessment criteria were used and little information was provided on studies that were excluded. This metaanalysis needs to be conducted again with more thoroughness and perhaps based more closely on the superior methodology used by the Cochrane Collaboration for systematic reviews. ${ }^{4}$

Felix S F Ram respiratory research fellow St Luke's Hospital, Bradford BD5 0NA felix.ram@email.bradh-tr.northy.nhs.uk Competing interests: None declared.

1 Shrewsbury S, Pyke S, Britton M. Meta-analysis of in symptomatic asthma (MIASMA). BMJ 2000:320:136873. (20 May.)

2 Dickersin, K, Scherer R, Lefebvre C. Identifying relevant studies for systematic reviews. BMJ 1994;309:1286-91.

3 Jadad AR, Moore RA, Carrol D, Jenkinson C, Reynolds DJ, Gavaghan DJ, et al. Assessing the quality of reports of randomized clinical trials: is blinding necessary? Contr Clin Trials 1996;17:1-12

4 Jadad AR, Moher M, Brownman GP, Booker L, Sigouin C, Fuentes M, et al. Systematic reviews and meta-analysis on treatment of asthma: critical evaluation. BMJ 2000; 320:537-40. (26 February.)

\section{Authors' reply}

EDITOR-In planning and conducting this trial we have aimed to adhere to current best practice, conducting our review to a predefined protocol (itself modelled on the 
guidance offered in the Cochrane Reviewers' $H_{\left.a n d b o o k^{1}\right)}$ and reporting it as recommended by the QUOROM statement. ${ }^{2}$ Our search was comprehensive: the Cochrane database yielded 263777 references for salmeterol recently; 17 mentioned both inhaled steroid and asthma in their title. Hand searching these showed no missing studies in our analysis.

We made effective use of our access to detailed study level materials, obtaining full clinical study reports and in many cases the raw data, which enabled a more comprehensive and standardised comparison across studies. The scale of measurement was prespecified, although in the case of exacerbations a change to odds ratio has no material effect on the conclusion presented: exacerbation rates were not increased with add-in salmeterol. Nine studies were identified by this review, and therefore subgroup analyses would have been of limited value. The more conservative random effects model showed greater benefit with added salmeterol.

Many doctors regard exacerbations of asthma as a reasonable guide to airway inflammation when measurement of bronchial hyperreactivity or biopsies are unavailable. Our finding of no increase in exacerbation rates with add-in salmeterol is supported by two bronchial biopsy studies by $\mathrm{Li}$ et $\mathrm{al}^{3}$ and Sue-Chu et al. ${ }^{4}$ In these, patients receiving salmeterol plus low dose inhaled corticosteroid (compared with increased corticosteroid) showed no increase in inflammatory cells (and fewer eosinophils ${ }^{3}$ or mast cells ${ }^{4}$ ) in the respiratory epithelium.

Salmeterol costs more than theophyllines. If cost were the only consideration in asthma treatment, however, we would still be using prednisolone for maintenance. Doctors will instead wish to weigh the potential for increased costs against the benefits of increased efficacy or improved safety, or both, when judging what is best treatment. A Cochrane review supports numerous studies showing superior efficacy and tolerability of salmeterol compared with theophyllines.

The weight that readers of our paper attach to it is for them to judge in the knowledge of our affiliations, openly stated. The value of this work is, we believe, that it addresses the dilemma at step 3 of the British Guidelines on Asthma Management. Other papers have compared the efficacy and safety of salmeterol with regular salbutamol, while concerns have been expressed about the overuse of short acting agents. We believe that our findings support the choice of adding in salmeterol as a superior alternative to increasing the dose of inhaled corticosteroids.

Stephen Shrewsbury associate medical director Stephen Pyke section head, respiratory statistic. Mark Britton consultant respiratory physician GlaxoWellcome UK, Uxbridge, Middlesex UB11 1BT

Sbs40926@glaxowellcome.com

Stephen Shrewsbury and Stephen Pyke are full time employees of GlaxoWellcome; Mark Britton has been taken to international conferences, has received fees for speaking at conferences and for research and a respiratory nurse, and has shares in GlaxoWellcome.

1 Clarke M, Oxman AD, eds. Cochrane reviewers' handbook 4.0 [updated July 1999]. In: Clarke M, Oxman AD, eds. Cochrane library [database on CD ROM] Cochrane Collaboration. Oxford: Update Software; 2000 , issue 1. Moher D, Cook DJ, Eastw MF. Im, Cook DJ, Eastwood J, Olkin I, Rennie D, Strou DF. Improving the quality of reports of meta-analyses of randomised controlled tri

3 Li X, Ward C, Thien F, Bish R, Bamford T, Bao X et al. An Li X, Ward C, Thien F, Bish R, Ban antiinflammatory effect of salmeterol, a long-acting beta2 agonist, assessed in airway biopsies and bronchoalveola lavage in asthma. Am $J$ Respir Crit Care Me 999;160:1493-9

4 Sue-Chu M, Wallin A, Wilson S, Ward J, Sandstrom T, Djukanovic $\mathrm{R}$ et al. Bronchial biopsy study in asthmatic treated with low and high dose fluticasone proprionat (FP) compared to low dose FP combined with salmeterol. Eur Respir J 1999;14 (suppl 30):124s.

\section{Arterial and venous disease and deep vein thrombosis}

Timing of thromboprophylaxis for general surgery should be discussed with anaesthetists

EDITOR-The prevention of deep vein thrombosis and pulmonary embolism is a major consideration in all surgical patients. Unfortunately, the anaesthetic implications of thromboprophylaxis are rarely discussed, and this was once again the case in the article by Gorman et al.

The authors recommend low dose unfractionated heparin for the prevention of deep vein thrombosis in general surgical patients. The regimen described causes little risk of serious surgical bleeding. However, spinal or epidural anaesthesia performed in a patient who had received this treatment would be potentially dangerous, as this is the time of high or peak anticoagulant activity. This increases the risk of vertebral canal haematoma, which can lead to permanent paraplegia. The risk can be reduced by not performing such procedures within four hours of the last dose of low dose unfractionated heparin.

Details on the use of low molecular weight heparin were lacking in the article despite its wide use. Recent recommendations from several European societies include delaying the insertion of spinal or epidural blocks for eight to 12 hours after giving low molecular weight heparin. ${ }^{3}$

In clinical practice, giving low molecular weight heparin at $8 \mathrm{pm}$ each evening, starting the day before surgery and continuing postoperatively, ensures that neuroaxial blockade is possible. A patient admitted on the morning of surgery in whom a neuroaxial block is to be undertaken will be mobile until the block is inserted. Low molecular weight heparin should then be given intraoperatively, at least one hour after the procedure, as recommended by Vandermeulen et al.

Neuroaxial blockade leads to a reduction of deep vein thrombosis and pulmonary embolism as well as relief of pain. Therefore discussion between anaesthetists and surgeons, to ensure that the timing of thromboprophylaxis does not lead to a neuroaxial block being contraindicated, is essential. This ensures that in the prevention of deep vein thrombosis and pulmonary embolism the risks are minimised and the benefits maximised.

We support the promotion of thromboprophylaxis by this article but are concerned that overall patient safety may be compromised because it did not mention the anaesthetic implications.

David Crossley consultant anaesthetist

Z Zych consultant anaesthetist

Princess Alexandra Hospital, Harlow, Essex CM20 1QX

1 Gorman WP, Davis KR, Donnelly R. ABC of arterial and venous disease: Swollen lower limb-1: General assessment venous disease: Swollen lower limb-l: General assessment and

2 Vandermeulen E, Aken H, Vermylen J. Anticoagulants and spinal epidural anesthesia. Anesth Analg 1994;79:1165-77 3 Horlocker T, Wedel D. Spinal and epidural blockade and peri-operative low molecular weight heparin: smooth sailing on the Titanic. Anesth Analg 1998;86:1153-6.

4 Barash PG, Cullen BF, Stoelting RK, eds. Clinical anesthesia. 2nd ed. Philadelphia: Lippincott, 1997:810-1.

Injecting drug use is major risk factor for deep vein thrombosis

EDITOR-Gorman et al's review article on general assessment of the swollen lower limb and deep vein thrombosis addressed many risk factors for the development of thromboembolic disease. ${ }^{1}$ It did not, however, recognise use of illicit injected drugs as another major risk factor.

In the population that I see, injecting drug use as a predisposing factor is apparent in over half of patients presenting with deep vein thrombosis in the leg. The hospital serves an inner city population similar to that of other large cities in Britain. Review of the literature (PubMed) showed few-and hardly any recent-references on this topic. ${ }^{2}$ An analysis of patients in South Africa who used injected drugs found deep vein thrombosis to be the admitting diagnosis in 12\% of a total of 121 admissions. ${ }^{3}$

Management of deep vein thrombosis in these patients is often complicated by several problems (homelessness, lack of compliance, further use of injected drugs), and anticoagulation with warfarin is not thought to be safe in most cases. Colleagues and I are at present using a combined approach together with our drug dependency unit to give dalteparin injections daily when patients attend the unit to collect their methadone. This issue has got important health economic and management aspects, and I propose that it be addressed in a larger scale audit to enable us to develop a working strategy.

$\mathbf{S} \mathbf{E}$ Baldeweg specialist registrar in general internal medicine and endocrinology and diabetes University College Hospital, London W1N 8AA

1 Gorman WP, Davis KR, Donnelly R. ABC of arterial and venous disease: Swollen lower limb-1: General assessment and deep vein thrombosis. BMJ 2000;320:1453-6. (27 May.)

2 Roszler MH, McCarroll KA, Donovan KR, Rashid T, Klin GA. The groin hit: complications of intravenous drug abuse. Radiographics 1989:9:487-508

3 Williams PG, Ansell SM, Milne FJ Illicit intravenous drug use in Johansell SM, Milne F. .llit intavenous drug use in Johannesburg-medical complications and pre
lence of HIV infection. $S$ Afr Med J 1997;87:889-91. 


\section{Babies sleeping with parents and sudden infant death syndrome}

\section{Invoking sudden infant death syndrome in cosleeping may be misleading}

EDITOR-Blair et al investigated the factors influencing the risk of the sudden infant death syndrome. ${ }^{1}$ In an increasing number of infant deaths that we have investigated over recent years we have found several recurring themes: infant under 3 months; shared sleeping arrangements, particularly sharing a sofa; young carer; consumption of alcohol the night before the infant was found dead. Typically, the infant is found between the adult and the back of the sofa, often covered by a duvet. Sharing a sofa seems to be particularly common in single parent households with poor socioeconomic support, in which the mother sleeps on the sofa, often with more than one child, simply because it is the warmest place in the house. Some of the risk factors highlighted by Blair et al have long been recognised in law in the Children and Young Persons Act 1933.

We are concerned with the use of the term sudden infant death syndrome in this paper because it is potentially misleading in deaths associated with cosleeping. In such cases the infant may have been accidentally overlaid, smothered by the bedclothes, or squashed between the adult and back of the sofa. We accept that this cannot, at present, be proved beyond reasonable doubt, but we found in a recent study that intra-alveolar haemorrhage was increased in infants who died in the context of bed sharing and that this may be a marker of accidental asphyxia. ${ }^{2}$ This often manifests as bloodstained fluid issuing from the nose and mouth with consequent bloodstaining of the bedding and infant's clothing. Examination of the clothing and bedding is therefore essential.

It is inappropriate to accuse a carer unjustly in a cosleeping death. Nevertheless, it strikes us as being more honest to raise the suspicion that accidental upper airway obstruction may be a factor in the death and to give the cause of death as unascertained while giving appropriate support to parents.

N Carter senior lecturer in forensic pathology G N Rutty senior lecturer in forensic pathology Medicolegal Centre, Sheffield S3 7ES

1 Blair PS, Fleming PJ, Smith IJ, Platt MW, Young J, Nadin P, et al. Babies sleeping with parents: case-control study of factors influencing the risk of sudden infant death syndrome [with commentary by $\mathrm{E}$ Mitchell]. BMJ syndrome [with
1999;319:1457-61

2 Yukawa N, Carter N, Rutty G, Green MA. Intra-alveolar haemorrhage in "sudden infant death syndrome": a cause for concern? J Clin Pathol 1999;52:581-7.

\section{Down with smoking and babies sleeping} in separate rooms

EDITOR-The finding of Blair et al that infants who sleep in a separate room are at a significantly increased risk of the sudden infant death syndrome is of critical importance but was not adequately empha- sised. ${ }^{1}$ This increased risk was about the same as that for infants sharing a bed, even including smokers. Considering that in the industrialised world sleeping in a separate room is much more common than sharing a bed, many lives could be saved by discouraging this separation.

Parents commonly let their babies "cry it out" in their cribs, often in a separate room. Eventually, the infants are conditioned not to cry at all. Many paediatricians promote this suppression of the babies' inborn instinct to cry and the mothers' natura instinct to respond by providing comfort, although there is no scientific evidence to show that this practice is safe or without long term effects.

The long bouts of crying evoke many physiological responses such as increased heart rate, body temperature, blood pressure, respiratory rate, and production of stress hormones. Overheating is especially worrying as this may be a factor in the sudden infant death syndrome.

Psychologically, infants may feel abandoned by being left alone for extended periods, a practice not shared by any other mammal or most human cultures, which have been practising cosleeping behaviour throughout their evolutionary history. ${ }^{3}$ Is it really fair, then, to ask our babies to simply shed their natural instincts, learnt over the course of millions of years, as if they were just a bad habit?

The evidence on the adverse effects of smoking during pregnancy and nursing is extensive, making it ludicrous to simply recommend mothers who smoke not to practise bedsharing, as Mitchell states in his commentary. ${ }^{1}$ It is time for the medical community to accept some of the responsibility for the many mothers who smoke and to take the lead in curbing it. How many doctors spend time counselling their patients about these dangers?

Edwards showed that exposure to chemicals in air fresheners may have adverse effects on babies. ${ }^{4}$ Perfumes, deodorants, and other products may contain similar chemicals, so they might also have negative impacts, especially in infants who share a bed and are snuggled up close to their mother throughout the night.

Instead of scaring parents, as some current guidelines do, ${ }^{5}$ the medical community should establish recommendations for parents to safely share a bed with their infants.

Cory A Mermer medical researcher and writer PO Box 3004, Westfield, NJ 07091, USA

1 Blair PS, Fleming PJ, Smith IJ, Platt MW, Young J, Nadin P, et al. Babies sleeping with parents: case-control study of factors influencing the risk of sudden infant death syndrome [with commentary by $\mathrm{E}$ Mitchell]. $B M$ J 1999;319:1457-6

2 Nelson EA, Taylor BJ, Wetherall IL. Sleeping position and infant bedding may predispose to hyperthermia and the sudden infant death syndrome. Lancet 1989;i:199-201.

3 Mosko S, Richard C, McKenna J, Drummond S, Mukai D. Maternal proximity and infant $\mathrm{CO}_{2}$ environment durin bedsharing and possible implications for SIDS research. Am J Phys Anthropol 1997;103:315-28.

4 Edwards R. Far from fragrant. New Scientist 1999;163.

5 American Academy of Pediatrics Task Force on Infant

Positioning and SIDS. Does bed-sharing affect on Infant

STIDS? Pediatrics 1997;100:272.
Smoking may be residual confounder in bed sharing

EDITOR-Blair et al provided some valuable evidence in their case-control study on the factors influencing the risk of the sudden infant death syndrome, particularly the dangers of an infant sharing a bed when the parents are smokers. ${ }^{1}$ Although they adjusted for parental smoking, we are concerned that it may still act as a residual confounder and hence be an alternative explanation for the apparent increased risk of the syndrome when infants share the parental bed.

In the full multivariate analysis maternal smoking during pregnancy and parental smoking are simply categorised as yes or no variables (table 3). Usual daily postnatal exposure to smoking is crudely estimated as either 0 or 1 or more hours a day. Clearly, exposure can vary hugely in these broad categories. Smoking could still be acting as a confounding variable if parents sharing a bed with their infant were more likely to smoke heavily or for longer periods in the home. Indeed, the authors note: "Among index mothers who smoked, more of those whose infants shared the bed smoked more than 20 cigarettes per day $(23.2 \% v 1.5 \%$ control) compared with those who did not bed share $(16.6 \%$ v 5.9\%)."

Similarly in the analysis of the risk of the sudden infant death syndrome by parental smoking and bed sharing (table 4) the infant's tobacco exposure is inadequately described. Parental smoking is adjusted for, but Blair et al do not specify how or whether infant exposure to smoke is included in the analysis.

We are also disturbed by the apparent lack of adjustment for smoking as a confounder in the simplified model (table 5). In particular, this table details high alcohol consumption as a variable. Since high maternal alcohol consumption is often accompanied by a similarly high prevalence of smoking, smoking may be responsible for some or all of the observed association.

We suggest that this paper may have been improved by using a greater number of categories to classify the extent of parental smoking prenatally and postnatally. In addition, an assessment of exposure to tobacco smoke immediately before the infant's last or reference sleep may have been beneficial, rather than relying on the usual daily exposure. We therefore believe that the increased risk of the sudden infant death syndrome in infants aged $<14$ weeks who share a bed and whose parents smoke is as yet unproved.

Amara Ezeonyeji stage 3 medical student Steph Jewitt stage 3 medical student Leigh Poyser stage 3 medical student Tom Stadward stage 3 medical student Department of Epidemiology and Public Health, University of Newcastle upon Tyne, Newcastle upon Tyne

1 Blair PS, Fleming PJ, Smith IJ, Platt MW, Young J, Nadin P, et al. Babies sleeping with parents: case-control study of syndrome [with commentary by E Mitchell]. BMJ 1999:319:1457-61. 


\section{Authors' reply}

EDITOR-Cause of death was established by a multidisciplinary committee after a full necropsy to a standard protocol including both a clinical history and a detailed description of the precise circumstances of death. Of the sofa sharing infants classified as sudden infant death syndrome, only $20 \%$ $(4 / 20)$ had blood stained fluid from the nose and mouth. Carter and Rutty suggest this is a marker of accidental asphyxia, but it is not uncommon in deaths from the syndrome in which accidental asphyxia was not suspected. Blood stained fluid was also found among 13\% (11/85) of infants with the syndrome who were found sleeping alone in a cot in a non-prone position without evidence of head covering (Fisher's exact test, $\mathrm{P}=0.48)$. Without further evidence from the necropsy or circumstances of death, the sudden infant death syndrome is the appropriate classification for infants found cosleeping on a sofa unless we wish to travel full circle and again attribute cause of death solely by the proximity of the parent.

The increased risk associated with infants sleeping in a separate room requires further investigation; $63 \%$ of the control infants shared the parental room, which should be viewed as the norm as in most societies worldwide. Recommendations for infants to sleep in a separate room from parents owe more to archaic views of child development than to scientific observation. We primarily addressed the issue of bed sharing, so where the infant slept was categorised in terms of the different forms of cosleeping. Room sharing needs to be looked at separately in terms of the time of day the sleep occurred, the type of sleeping place, and who else was present. Our preliminary findings suggest that the risks associated with infants sleeping on an adult bed alone are greater than when a parent is sharing the bed, especially among comparatively older infants who can move under the adult covers.

Infant exposure to tobacco smoke is a strong risk factor for the syndrome but does not in itself explain the disproportionate number of deaths occurring in adult beds. We collected data on the number of cigarettes smoked by the parents and the number of hours of daily infant exposure. In the large multivariate model, adjusting for the different doses of cigarettes smoked or hours of exposure had the same minimal effect on bed sharing as using dichotomous variables. In the more restricted model (controlling for adverse bed sharing conditions) we did not measure recent exposure to tobacco smoke. Adjusting for smoking using a proxy measure of infants usually exposed to high levels of tobacco smoke had little effect on the results. The risk associated with bed sharing cannot be explained by the residual confounding associated with tobacco exposure, but the reduced number of deaths occurring in the adult beds of non-smokers suggests it can only be generalised to infants of parents who smoke.

Peter Blair medical statistician

Peter Fleming professor of infant health and developmental physiology

Institute of Child Health, Royal Hospital for Children, Bristol BS2 8B

Martin Ward Platt consultant paediatrician and senior lecturer in child health

Newcastle Neonatal Service, Royal Victoria

Infirmary, Newcastle upon Tyne NE1 4LP

\section{Global medical knowledge database}

\section{IT, or not IT?}

EDITOR-The vision of the future proposed by Dawes and Godwin is an excellent one that can only enhance the knowledge of doctors worldwide and in turn lead to better patient care.

Unfortunately, as with most excellent ideas, there is still no materialisation within sight. This goes to emphasise how the NHS, owing to underfunding and the continued use of reactive rather than proactive strategies, is ill equipped to cope with large amounts of information.

Hospitals are way behind when it comes to the implementation of corporate intranets. These could be used to hold information on local medical guidelines, and are therefore an important issue in risk management. The local internal telephone directory could be incorporated, obviating the need for expensive reprinting and distribution of paper telephone directories that become rapidly out of date and allowing instantaneous update with correct information. The same could apply every six months when the new intake of junior doctors arrives and one wishes to find out their bleep numbers.

The antiquated system of temporal note keeping needs to be addressed as a matter of urgency. I spent 30 minutes reading every page of a patient's notes just to construct a table of how the patient's weight varied over the past three years. Computer systems in different departments of the same hospital cannot talk to each other. There is too much duplication of information. Computerised notes would allow a full discharge summary to be sent to the general practitioner immediately upon the patient's discharge. Logical notes with problem lists and current management plans would allow greater continuity of care, especially on call. Thyroid function tests would not be repeated three times within a week because the system would automatically tell you they had been done and display the results. It has been shown that computers can be useful and reduce errors made by doctors. ${ }^{2}$ When are we going to learn that computerisation will not replace our medical knowledge and training but merely augment it and allow better, more efficient, and safer delivery of care to our patients?

Paul Davison senior house officer, general medicine Leicester General Hospital, Leicester LE5 4PW p.davison@btinternet.com
1 Dawes M, Godwin M. Global medical knowledge database is proposed. BMJ 2000;320:1340. (13 May.)

2 Nightingale PG, Adu D, Richards NT, Peters M. Implementation of rules based computerised bedside prescribing and administration: intervention study. BMJ 2000;320:750-3.

\section{New professional obligation arises}

EDITOR-Some time ago I invented a new professional obligation, which Dawes and Godwin have peripherally recognised without making explicit. ${ }^{1}$

A doctor who accesses the world wide web-which is, in principle at least, the sum total of searchable and publicly exposed knowledge of the human race, our species's common capital of the mind-to seek the answer to a question but does not find it there and has the facility to place material on the web, and who later finds some part of an answer by reading books, or experiment, or asking colleagues, or prolonged introspection must place that answer on the web where the next one to ask the same question can find it. The "warm fuzzy" emails that can result from obeying this new professional obligation are worth some work, trust me.

Adrian Midgley general practitioner

Homefield Surgery, Exeter EX1 2QS

midgley@mednetics.org

1 Dawes M, Godwin M. Global medical knowledge database is proposed. BMJ 2000;320:1340. (13 May.)

\section{Second editorial on GMC is ironic}

EDITOR-Smith's second editorial on the General Medical Council in recent weeks was characteristically cogent and pointed but is ironic for various reasons. ${ }^{1}$ The first editorial on the subject was influential in raising questions about the continuing existence of the organisation and of the supposed unpopularity of its president. ${ }^{2}$ It is therefore perhaps not surprising that the BMA, at its annual representative meeting in July, should carry a motion expressing "no confidence" in the GMC, albeit surrounded by qualifying amendments in order to soften its impact. It is reassuring that Smith now takes the view that GMC leaders should not be put to the sword and that doctors must work together. It is a great pity that the problems the GMC faces in managing the media were not expressed in the original piece, let alone the tardy recognition that it has come into the firing line probably unfairly.

Smith also correctly identified that most of the speakers against the no-confidence motion were general practitioners. Given that hospital specialists and their junior colleagues are already exposed to institutional scrutiny of standards of practice, as opposed to a far less rigorous existence in general practice, it is even more ironic that most of the resistance to revalidation should come from the former group.

The third irony is that the same meeting backed revalidation overwhelmingly, that the GMC is already moving towards a new structure and arrangements for governance, and that, as soon as the dreaded words "no" 
and "confidence" were uttered in the same sentence, peace broke out. All parties now seem anxious to have a dialogue in the name of the preservation of medicine as a profession.

The British medical profession now needs a rallying point about which to restore its flagging morale and loss of direction. Some may choose the latest attempt to reorganise the NHS, others will put their faith in their medical royal college or the BMA. I am a doctor because I am registered with the GMC, not because of any contractual arrangement with the NHS or member ship of a college or professional organisation. I will support a future for the GMC as a primary professional focal point, if for no other reason than that it is prepared to take a courageous stance for good medical practice in the face of so many sectional interests.

Brian D Keighley elected GMC member for Scotland The Clinic, Buchanan Street, Balfron, Stirlingshire, G63 0TS

bkeighley@compuserve.com

Smith R. Should GMC leaders be put to the sword? $B M$ / 2000;321:61. (8 July.)

2 Smith R. The GMC: where now? BMI 2000;320:1356. (20 May.)

\section{Isolated systolic hypertension}

Is it time for me to retire from medicine? EDITOR-I quit English when I found that all the theses and the few monographs or surveys on the topic I wanted to know about (in that case love poetry) failed to define their terms. They plunged into their topic without having the faintest idea of what they were writing about, or if they did have they didn't let on.

I now have a strange sense of déjà vu: how is it possible for authors to write an article-and get it published in the $B M J$ no less-without letting on what it is they are talking about? What is systolic hypertension? ${ }^{1}$ Over 125 or 134 or 143 or 150 or $160 \mathrm{~mm} \mathrm{Hg}$ ? This remains a mystery. So any discussion or communication is impossible, as we do not have a mutually agreed definition of terms.

The technical terms systolic pressure, diastolic pressure, mean arterial pressure, etc are clear enough, but, curiously, what should be most objective-numeration-is least so. Even if you mention a number the problems of definition are only beginning. One reading, two, 10; the mean or the highest or, perhaps to be scientific or at least rigorous, plus or minus 1 or $2 \mathrm{SD}$ ?

We still haven't touched on interobserver variability or instrumental variation-for example, aneroid or mercury sphygmomanometer variation-or temporal or indeed location differences. Doctor's surgery, hospital accident and emergency department, pharmacy, doctor, nurse, female versus male; all these give sometimes distinct readings-so much so that a hypertensive patient becomes normotensive or vice versa. Finally, the only reliable method (which of course is prohibitively expensive)-24 hour blood pressure monitoring-itself is either highly suspect or not yet normative.

So pray tell, what do you mean when you utter the words systolic hypertension? I have a definition of love poetry but not of the topic at issue.

Alexander J N I F Jablánczy general practitioner 955 Oueen Street, Sault Sainte Marie, Ontario

Canada

aljablan@sympatico.ca

1 Wilkinson IB, Christison DJW, Cockroft JR. Isolated systolic hypertension: a radical rethink. BMJ 2000;320:1685 (24 June.)

\section{Life assurance industry highlights} importance of blood pressure control

EDITOR-Wilkinson et al's editorial on isolated systolic hypertension was a useful reminder to all clinicians of the importance of pulse pressure. ${ }^{1}$ But the authors do a disservice to the life assurance industry when they allege that we have relied excessively on measurements of diastolic pressure. If they would refer both to the reassurers' manual and to the standard textbook on the subject they would see that both systolic and diastolic pressures have been taken into account for many years when applicants are assessed for life and disability assurance.

The life assurance industry and the doctors who specialise in insurance medicine have done more than most to highlight the importance of good blood pressure control in reducing both mortality and morbidity risks. We shall continue to do so.

Geoffrey H Robb president

Assurance Medical Society, London W1M 0EB

1 Wilkinson IB, Christison DJW, Cockroft JR. Isolated systolic hypertension: a radical rethink. BMJ 2000;320:1685. (24 June.

2 Brackenridge RDC. Medical aspects of life assurance. London: Staples, 1962.

Brackenridge RDC, Flder WJ. Medical selection of life risks. 4th ed. London: Macmillan Reference, 1998.

\section{Disability one year after head injury}

\section{Role of alcohol needs to be examined}

EDITOR-Thornhill et al in their paper on disability in young people and adults after head injury show again the extent to which alcohol misuse contributes to head injury. Sixty-nine per cent described alcohol as being involved or suspected in the history, and in 39\% drinking was excessive or requiring treatment.

In the follow up at one year there is no evidence of any advice or treatment for alcohol misuse received after the head injury. Alcohol misuse may well have had contributed significantly to the poor outcome of rehabilitation at the end of one year. It has been shown in a general hospital that even a single session of alcohol counselling from a nurse, for up to an hour, produced appreciable health benefits at the close of a year.? Several comparable studies have shown similar outcomes, but the number of interventions of this kind in general hospitals in the United Kingdom has not increased.

I would be interested to know if the authors believe that the effective treatment of alcohol problems would have improved the rehabilitation outcome. The presence of alcohol related brain damage may also have contributed to the poor outcome even when the amount of injury was comparatively slight. The study by Thornhill et al provides further evidence that much alcohol misuse shows up in the accident and emergency and acute wards of our general hospitalsand yet little action is taken to change this, despite the cost to the NHS.

E B Ritson consultant psychiatrist Alcohol Problems Clinic, Royal Edinburgh Hospital, Edinburgh EH10 5HF

bruceritson@netscapeonline.co.uk

1 Thornhill S, Teasdale GM, Murray GD, McEwen J, Roy CW, Penny NI. Disability in young people and adults one year after head injury: prospective cohort study. BMJ after head injury: prosp

C. Counselling problem drinkers in medical wards: a controlled study. BMJ $1985 \cdot 990 \cdot 965-7$

\section{Authors' reply}

EDITOR-The reasons for a poor outcome after an apparently mild head injury need further investigation to determine the importance of the various factors that may be responsible. In addition to previous health, the severity of the injury, and early complications, it seems likely that subsequent social factors-including the extent of the support received and the lifestyle-are important.

Clearly alcohol misuse may be relevant so that interventions of the kind described by Chick may be helpful as one component of a more broadly based approach to the problems of the patient with head injury.

\section{Sharon Thornhill research assistant}

Graham M Teasdale professor

Department of Neurosurgery, University of Glasgow, Southern General NHS Trust, Glasgow G51 4TF

Gordon D Murray professor of medical statistics Department of Community Health Sciences, University of Edinburgh, Edinburgh EH8 9AG

James McEwen professor of public health University of Glasgow, Glasgow G12 8QQ Christopher W Roy consultant in rehabilitation medicine

Southern General NHS Trust, Glasgow G51 4TF

Kay I Penny research fellow

Department of Community Health Sciences, University of Edinburgh

\section{Upward trend in acute anaphylaxis continued in 1998-9}

Editor-Sheikh and Alves's paper ends with the introduction of ICD-10 (international classification of diseases, 10th revision) in figures for 1995-6; the authors rightly stated that the change in classification could affect results. ${ }^{1}$ ICD-10 subdivided anaphylaxis into four categories: 
Admissions with primary diagnosis of anaphylactic shock among patients treated in England 1995-6 to 1998-9. Figures are numbers (percentages)*

\begin{tabular}{lccccc} 
& \multicolumn{3}{c}{ Category under which reaction was classified } & & \multirow{2}{*}{ Oear } \\
\cline { 2 - 5 } Yeall No \\
\hline $1995-6$ & Food & Unspecified & Serum & Medicinal substance & Over \\
\hline $158(31.5)$ & $229(45.7)$ & $1(0.2)$ & $113(22.6)$ & 501 \\
\hline $1996-7$ & $312(37.1)$ & $366(43.6)$ & $9(1.1)$ & $153(18.2)$ & 840 \\
\hline $1997-8$ & $390(35.6)$ & $513(46.8)$ & $10(0.9)$ & $183(16.7)$ & 1096 \\
\hline
\end{tabular}

*Source: Hospital episode statistics.

reaction to food (T78.0), unspecified (T78.2), serum (T80.5), and medicinal (T88.6). With this change, the numbers dropped to 501 admissions in 1995-6. Such swings are not uncommon when new classification systems are introduced.

Hospital episode statistics are now available for 1998-9, and the coding discrepancy seems to have been resolved: the number of admissions for anaphylaxis increased to the level recorded in 1994-5 and now exceeds it (an admission being uniquely identified as the first episode in a spell). In 1998-9 there were 1202 admissions, or 11.05/100 000 admissions; this compares with 876 discharges (10.2/100 000 discharges) reported in 1994-5 (table).

Sheikh and Alves asked for more detailed reporting of vaccines causing an anaphylactic reaction, and there is better provision of this information in ICD-10; the latest data report the type of medicine involved. For example, in 1998-9 there were 76 acute anaphylactic shocks due to an adverse reaction to penicillin, 17 to hydroxyquinoline derivatives, and 16 to propionic acid derivatives. The additional information presented here further strengthens the need for more detailed research into the reasons underlying this escalating trend and on the longer term outcomes.

Richard Wilson research fellow

Department of Public Health and Epidemiology, Medical School, University of Birmingham,

Birmingham B15 2TT

r.c.wilson@bham.ac.uk

I thank the Department of Health for access to the hospital episode statistics via the safe haven pilot.

1 Sheikh A, Alves B. Hospital admissions for acute anaphylaxis: time trend study. BMJ 2000;320:1141. (27 May.)

\section{Provision of age appropriate health services for young people has been ignored}

EDITOR-In arguing for better coordinated psychological, sexual, and social health care for young people, Bennett and Bauman depict adolescence as a time of risky behaviours, including risky sex, delinquency, and drug misuse. ${ }^{1}$ There is incontrovertible evidence that mental health problems, drug misuse, and sexual problems are often comorbid in this population. But understanding this as a function of adolescent risk taking secondary to impaired decision making abilities is both pejorative to young people and unhelpful in planning health services for them. Old misconceptions of adolescents as risk takers with poor future thinking abilities are largely false and therefore unhelpful. ${ }^{2}$

Most adults take as many risks as most young people do and have equally poor future thinking abilities. Indeed, the same comorbidities of mental health problems, drug use, and sexual risk taking can be seen in adults. ${ }^{3}$ That adults sometimes seem to take fewer risks is largely because they have learnt the consequences of their youthful experimentation

It is far more helpful to understand so called risk taking behaviours in young people as developmentally appropriate exploratory behaviours-that is, young people exploring, and learning from, the many possible adult behaviours open to them. Young people have distinct health needs and respond best to health services knowledgeable about adolescent development. ${ }^{4}$ Portraying young people as substantially different from adults is understandably seductive to those who are keen to improve adolescent health. It can be counterproductive, though, in aiding the political and social construction of young people as a dangerous group who require increased levels of social control. $^{5}$ This effectively excludes young people from mainstream services and detracts from the search for effective interventions.

We strongly share with the authors the aim of improving adolescent health and health services for young people. Improved services are needed not because adolescents have precarious health due to risk taking but because the provision of age appropriate health services for young people has been largely ignored and because young people tell us that they frequently find existing health services unhelpful, paternalistic, and difficult to access. ${ }^{4}$

Russell Viner consultant in adolescent medicine University College London Hospitals and Great Ormond Street Hospital, Middlesex Hospital, London W1N 8AA rviner@ich.ucl.ac.uk

Aidan Macfarlane freelance specialist in maternal, child, and adolescent health

6 Cobden Crescent, Oxford OX14LJ

1 Bennett DL, Bauman A. Adolescent mental health and risk sexual behaviour. BMJ 2000;321:251-2. (29 July.)

2 Males M. Adolescents: daughters or alien sociopaths Lancet 1997;349(suppl 1):I13-6.

3 Cohen ED. An exploratory attempt to distinguish subgroups among crack-abusing African-American women. J Addict Dis 1999;18:41-54.

4 MacFarlane A, McPherson A. Primary health care and adolescence. BMJ 1995;311:825-6.

5 Griffin C. Representations of the young. In: Roche J,

Triffin C. Representations of the young. In: Roche J,
Tucker S, Youth in society. London: Sage, 1997:17-25.

\section{Emergence of multidrug resistant pneumococci in India}

Editor-The World Health Organization warns of the emergence of superbugs, according to a news article by Kmietowicz. ${ }^{1}$

I have been a consulting paediatrician in Bijnor, a small district in western Uttar Pradesh, India, since 1992. During the past 10 months I have treated seven cases of drug resistant pneumoccocal meningitis. The patients were aged between 2 and 14 years, and all of them were resistant not only to penicillin but also to commonly used third generation cephalosporins-namely, cefotaxime and ceftriaxone. The diagnosis was based on the results of Gram staining and culture sensitivity reports in cerebrospinal fluid. All of the children were given vancomycin, after which only three children showed an improvement and two died. Three children were left with severe neurological problems and were lost to follow up.

This report highlights the emergence of drug resistant serious pneumococcal infections in the community, a phenomenon hitherto unknown in India. Reports of penicillin resistant pneumococci have been numerous from developed countries, but such resistance has not been a problem in the Indian subcontinent. The arrival of resistant pneumococci was, however, long overdue here, given the degree of inadvertent and irrational use of third generation cephalosporins and other newer antimicrobials in certain trivial infections that ideally required none-for example, viral bronchitis, infections of the upper respiratory tract, diarrhoea, and viral croups. In a country where quacks are able to prescribe allopathic medicines, antibiotics are prescribed at the drop of a hat, most practitioners do not have access to good investigation facilities, and a policy on the use of antibiotics is almost totally lacking, it is rather surprising that conventional antibiotics were still holding sway over a micro-organism that had become resistant to most of them elsewhere in the world.

Vipin M Vashishtha consultant paediatrician Mangla Hospital, Shakti Chowk, Bijnor-246 701, Uttar Pradesh, India

vmv9@vsnl.com

1 Kmietowicz Z. WHO warns of threat of "superbugs." BMJ 2000;320:1624. (17 June.)

\section{When people would choose treatment has wide implications}

EDITOR-Steel's paper on the thresholds for number needed to treat at which health professionals and lay people would choose treatment for hypertension is important. Only people with a particular condition can decide whether the inconvenience of treatment is worth the resulting reduction in risk. We cannot presume to know on their behalf. This view of personal autonomy is enshrined in the General Medical Council's advice on obtaining informed consent. 
Normally, if patients do not want to make a decision about treatment they opt to follow a health professional's recommendation. Unless it is informed by information on lay preferences, that recommendation is likely to result in systematic overtreatment. Risk thresholds for intervention chosen by lay people are much higher than those chosen by general practitioners and specialists. Most guidelines are written by experts.

The modal five year number needed to treat to prevent a death that was chosen by lay people was 33. This corresponds to a $3 \%$ reduction in absolute risk of death, which (since 1 in 3 events results in death) in turn corresponds to a $9 \%$ reduction in absolute risk of a cardiovascular event. If lay people judge a $9 \%$ reduction in risk of death to be the point at which treatment becomes worthwhile this means that treatment should be recommended when their five year risk is $30 \%$ (treatment typically reduces cardiovascular risk by $30 \%$, and $30 \% \times 30 \%=9 \%$ )

This contrasts sharply with the joint British recommendations on the prevention of cardiovascular disease in primary care. These regard intervention at a five year threshold of $15 \%$ as mandatory and at a five year threshold of $7.5 \%$ as to be considered. (These figures correspond to a five year number needed to treat to prevent a death of about 75 and 125 respectively; not surprisingly, these lie between the thresholds chosen by general practitioners and specialists as these two groups were the main authors of the guidelines)

What happens if we take the lay public's view of when treatment is appropriate? We would not recommend treatment for any non-diabetic woman under 60 or any non-diabetic man under 50. (None is at sufficiently high risk for us to believe that they might want treatment.) We should therefore perform routine blood pressure checks in these people only if we explicitly know that they would want treatment at lower risk thresholds than most of the population would. In other words, we need some form of informed consent to screen such patients routinely.

The findings of this paper need to be confirmed.

Tom Marshall lecturer in public health medicine University of Birmingham, Birmingham B15 2TT MarshaTP@PCR-FS1.bham.ac.uk

1 Steel N. Thresholds for taking antihypertensive drugs in different professional and lay groups: questionnaire survey. BMJ 2000;320:1446-7. (27 May.)

\section{Anaesthesia is also risky in patients with porphyria}

EDIToR-Thadani et al, in their review of the diagnosis and management of porphyria, comment on the risk of surgery but place insufficient emphasis on the potential hazards of anaesthesia for this group of patients. ${ }^{1}$ For patients with porphyria, anaesthesia carries a significant risk of morbidity and mortality, although most can now have surgery with comparative safety as a result of modern techniques in anaesthesia and the develop- ment of pharmacological agents with shorter half lives. ${ }^{2-5}$ Further improvements in anaesthesia safety depend on earlier detection of susceptible patients and the identification of potentially porphyrinogenic agents, neither of which may be readily achievable. Any patient with proved or suspected porphyria should be referred for early anaesthetic assessment if surgery is contemplated.

Susan deC Baker anaesthetic senior house officer HaHara@aol.com

Bruce Taylor consultant

Department of Anaesthesia, Queen Alexandra Hospital, Portsmouth PO19 4SE

1 Thadani H, Deacon A, Peters T. Diagnosis and management of porphyria. BMJ 2000;320:1647-50. (17 June)

ment of porphyria. BMJ 2000;32 0 . 1647-50.(17 June.) porphyric patient. Anaesthesia 1993;48:417-21.

3orphyric patient. Anaesthesia $1993 ; 48: 417-21$. James MFM, Hift

2000;85:143-53.
Jensen NF, Fiddler DS, Striepe V. Anaesthetic considera4 Jensen NF, Fiddler DS, Striepe V. Anaesthetic co
tions in porphyrias. Anaesth Analg 1995;80:591-9.

5 Ashley EM. Anaesthesia for porphyria. Br J Hosp Med 1996;56:37-42.

\section{Presumed consent further undermines medical ethics}

EDITOR-The proposed campaign for presumed consent for organ donation brings to mind the phrase with which Ronald Reagan demolished his presidential opponent: "There you go again."

We have had guidelines sanctioning the withdrawal of nutrition and hydration from patients if this is judged by their doctors to be "in their best interests." Then there was the dismissal of doctor assisted suicide, despite the majority of the population being in favour of merciful release from intractable and avoidable suffering. Now there is a public relations effort to seek acceptance of doctors taking any organs they wish from dead patients without explicit permission. Given the scandal of doctors' "professional arrogance" in presuming parents' consent to the wholesale removal of organs from their children, ${ }^{2}$ it is no wonder the BMA acknowledges that simply campaigning for a change in the law would be a waste of time.

Presumed consent runs counter to the principle of protecting patients' right to fully informed agreement. It clashes with current thinking, which is moving towards the idea of involving patients fully in treatment decisions. No administrative system could guarantee that there would never be an instance where an assumption of agreement later turned out to be wrong.

The campaign for presumed consent confirms that it is unacceptable that people with vested interests deem themselves suitable judges of what is medically ethical. Donation of organs is the ultimate gift, not a moral obligation.

Roger M Goss director

Patient Concern, PO Box 23732, London SW5 9FY rogerconcern@hotmail.com

1 Public must be informed about presumed consen [Medicopolitical digest]. BMJ 2000;321:119. (8 July.)

2 Bristol Royal Infirmary Inquiry. The inquiry into the management of care of children receiving complex heart surgery at the Bristol Royal Infirmary. (Interim report): Removal and retention of human material. Bristol: Bristol Roval Infirmary Inquiry, 2000.

\section{Eating disorders are becoming more common in the East too}

EDITOR-I support the urge for a more responsible media attitude on body image, ${ }^{1}$ not only in the United Kingdom but in Asian countries as well. A decade ago anorexia nervosa was rare outside the developed West. Now, however, it is becoming a common clinical problem among young women in Hong Kong and other high income Asian societies, such as Japan, Singapore, Taiwan, and the Republic of Korea. At the same time as economic liberalisation has led to the deregulation of media advertising, eating disorders have also appeared in major cities in low income Asian countries, such as China, India, Malaysia, the Philippines, and Indonesia. Community studies in Hong Kong indicated that 3-10\% of young women had disordered eating of a degree that warrants concern. ${ }^{2}$

Patients with eating disorders often attend several practitioners before they receive some sort of psychological treatment; these referrals have increased considerably since the late $1990 \mathrm{~s}$, and ever younger subjects are referred. It is alarming that this condition has appeared even though young Asian women are constitutionally slim by the standard of Western women. The depiction of ridiculously slender women in advertisements for virtually all kinds of commercial products must necessarily contribute to dissatisfaction with the body and disordered eating, especially in vulnerable individuals.

Media advertising cannot be the only social determinant of eating disorders. In all likelihood, societal modernisation intensifies vulnerability to eating disorders in women. If patriarchal sociocultural influences that are disempowering to women have a substantial role in eating disorders, we must remember that these forces are strong in Asian societies.

The rising rate of eating disorders will pose a public health challenge in the East. A change of media attitudes can almost certainly help, but Asian women may find the economic forces that maintain those attitudes simply insurmountable.

Sing Lee director

Hong Kong Eating Disorders Centre Medical Faculty, Chinese University of Hong Kong,

Hong Kong, China

singlee@cuhk.edu.hk

1 Morant H. BMA demands more responsible media attitude on body image. BMJ 2000;320:1495. (3 June.)

2 Lee S, Lee AM. Disordered eating in three communities of China: a comparative study of female high school students in Hong Kong, Shenzhen, and rural Hunan. Int J Eating Dis in Hong Kong, She

3 Waterson L. Dying to be thin. Reader's Digest 2000;May: $26-32$.

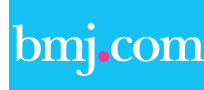

Rapid responses

Correspondence submitted electronically

is available on our website 